\title{
Interdicciones feéricas: la prohibición del habla y de la vista en torno a Melusina y Oberón en El unicornio (1965), de Manuel Mujica Lainez ${ }^{1}$
}

JUAN MANUEL LACALLE Universidad de Buenos Aires, Argentina / lacallejuanmanuel@gmail.com

\section{Resumen}

En este artículo nos detendremos, en primer lugar, en el análisis de algunas implicancias de la naturaleza feérica, a partir del dualismo morganiano-melusiniano, del personaje de Melusina en la novela histórica $E l$ unicornio (1965), del argentino Manuel Mujica Lainez. En un segundo momento veremos su contrapunto con la aparición del hada Oberón en la misma novela, en contraste con su presentación en las textualidades medievales, fundamentalmente en Huon de Bordeaux (ca. 1260). El relato del baño de Melusina y los episodios con Oberón enmarcan toda la aventura, ya que abren y cierran, respectivamente, la novela mediante raccontos de acontecimientos transcurridos en pasados inciertos, previos a la narración principal. Finalmente, y a partir del tratamiento y reescritura que Mujica Lainez hace de los personajes feéricos, nos focalizaremos sobre las prohibiciones que atañen a la vista y el habla y cómo esto se resignifica particularmente en la trama de El unicornio. Partiremos de la hipótesis de que las imposibilidades de concreción amorosa de estos personajes son consecuencia del incumplimiento o imposición de estas interdicciones y que la condena a la inmortalidad es un reflejo de la permanencia de condicionamientos socioculturales que persisten a lo largo de los siglos.

\section{Palabras clave: novela histórica / medievalismo /}

literatura argentina / hadas / Melusina

\section{Fairy interdictions: the prohibition of speech and sight around Melusine and Oberon in El unicornio (1965), by Manuel Mujica Lainez}

Abstract

In this paper, firstly, we will take to the analysis of some implications of the fairy nature, from the MorganeanMelusinean dualism, of Melusine character in the historical novel El unicornio (1965), by the Argentine Manuel Mujica Lainez. In a second moment we will see its counterpoint with the appearance of the fairy Oberon in the same novel, in contrast with its presentation in the medieval textualities, mainly in Huon de Bordeaux (ca. 1260). The story of Melusine's bath and the episodes of Oberon frame the whole adventure, since they open and close, respectively, the novel through raccontos of events that took place in uncertain pasts, previous to the main narration. Finally, and from the treatment and rewriting that

Recibido: 25/5/2019. Aceptado: 9/11/2019

Para citar este artículo: Lacalle, J.M. (2020). Interdicciones feéricas: la prohibición del habla y de la vista en torno a Melusina y Oberón en El unicornio (1965), de Manuel Mujica Lainez. El taco en la brea, 11 (diciembre-mayo), 31-46. Santa Fe, Argentina: UNL. DOI: 10.14409/tb.v1i11.9152 
Mujica Lainez makes of the fairy characters, we will see the prohibitions that affect sight and speech and how this is resignified particularly in the plot of El unicornio. We will start from the hypothesis that the impossibilities of amorous concretion of these characters are a consequence of the failure or imposition of these interdictions and that the condemnation of immortality is a reflection of the permanence of sociocultural conditionings that persist throughout the centuries.

Key words: historical novel / medievalism / argentine literature / fairies / Melusine

El unicornio es una novela histórica de temática ${ }^{2}$ medieval del argentino Manuel Mujica Lainez (1910-1984), ${ }^{3}$ publicada en 1965. En conjunto con Bomarzo (1962), la novela más conocida de este autor, ${ }^{4}$ y El laberinto (1974), que transcurren en la Italia renacentista y en el siglo XVI español, conforman el grupo de novelas históricas ancladas en el territorio europeo al que Sandro Abate denominó «el tríptico esquivo» (2004). ${ }^{5}$ De estas tres novelas se conservan en la actual Casa Museo "El Paraíso», en la provincia de Córdoba (Argentina), cuadernos manuscritos de notas autorales, a modo de respaldo documental, con distintas reflexiones sobre la construcción de los textos y con anotaciones bibliográficas, sumamente provechosos para potenciales trabajos de crítica genética. Específicamente sobre El unicornio, Abate señala: «llevó seis cuadernos, pero casi todos ellos dedicados al resumen del libro de René Grousset, Histoire des Crosades et de Royaume Franc de Jerusalén (1934) y a datos relativos a las leyendas y artes medievales» (21). ${ }^{6}$ Además, agrega sobre el vínculo con lo histórico, nunca se llega a incurrir en anacronismos en pos de eficacia discursiva. ${ }^{\text {? }}$

Una particularidad que distingue a esta novela histórica de otras es el lugar relevante que dedica a los componentes del imaginario medieval vinculados con lo literario. Tanto lo histórico como la ficción narrativa moderna se entrelazan con la textualidad medieval. ${ }^{8}$ Allí, el hada Melusina narra, de manera retrospectiva y en primera persona del singular, distintos episodios de su vida hacia finales del siglo XII: «En la época que evoco —el año 1174—», señala promediando el primer capítulo, y «reunidos alrededor del leproso, durante el festín de octubre de 1177», precisa al final del sexto ( $E U, 2009,15$ y 283). ${ }^{9}$ Los hechos narrados transcurren entre 1174 y 1185 , y el recuerdo parte de un momento actual impreciso, aunque varios detalles que se van intercalando a lo largo del relato nos ubican en un contexto cercano a la actualidad de publicación de la novela. ${ }^{10}$ La cualidad de inmortal del hada y su rol de narradora permiten a Mujica Lainez poner en boca del personaje una serie de consideraciones metanarrativas y de reflexiones críticas de la sociedad contemporánea a la publicación del texto. Estos aspectos otorgan la posibilidad de narrar sucesos del pasado con una perspectiva moderna y un grado alto de autoridad y de verosimilitud, al haber sido Melusina testigo de los hechos del siglo XII en adelante.

El análisis que realizaremos en este artículo se enfoca teóricamente desde el medievalismo, subdisciplina con mucho desarrollo en los últimos años y que se ha visto consolidada en compilaciones como The Cambridge Companion to Medievalism (D'Arcens) y Medievalism: A Manifesto (Utz)." En esta línea investigativa se ubican los trabajos sobre producciones como las novelas históricas que emplean el imaginario medieval para la construcción de nuevas ficciones a partir de escenarios, episodios y personajes de la Edad Media. A modo general, hay que tener en cuenta que los ejemplos de medievalismo en Latinoamérica, y sobre todo en Argentina, son escasos, y suelen 
estar más ligados al territorio español. Por ello, no debe soslayarse la singularidad de la novela sobre la que nos abocaremos. ${ }^{12}$

En los próximos apartados nos proponemos, en primer lugar, observar algunas de las implicancias de la naturaleza feérica del personaje de Melusina en El unicornio, tomando como base el dualismo morganiano-melusiniano (tal como lo postula Harf-Lancner). En segundo lugar, esto será contrastado con la aparición de Oberón, el otro hada con fuerte presencia en la novela, en contrapunto con su presentación en las textualidades medievales, para ver cómo operan y se resignifican los personajes de ambas hadas en el binomio mencionado. Desde un punto de vista estructural y narrativo consideramos que estos seres maravillosos, tomados del imaginario medieval literario o legendario, son relevantes puesto que el relato del baño de Melusina y los episodios con Oberón enmarcan toda la aventura, ya que abren y cierran, de manera respectiva, la novela mediante raccontos de acontecimientos transcurridos en pasados inciertos, previos a la narración principal. Por último, y a partir del tratamiento y reescritura que Mujica Lainez hace de los personajes feéricos, nos detendremos sobre las prohibiciones que atañen a la vista y el habla para observar cómo esto se resignifica particularmente en la trama de El unicornio. Partimos de la hipótesis de que las imposibilidades de concreción amorosa de estos dos personajes son consecuencia del incumplimiento o imposición de estas interdicciones, y que la condena a la inmortalidad ${ }^{13}$ es un reflejo de la permanencia de condicionamientos socioculturales que persisten a lo largo de los siglos, en este caso, veremos, asociados a la censura del travestismo y la homosexualidad en el marco de una relación amorosa.

\section{La leyenda de Melusina y el modelo de hada melusiniano}

El texto se estructura en nueve capítulos que nos presentan numerosos relatos. ${ }^{14}$ El primero, a modo de breve prólogo, se aboca a recordar de manera sucinta la leyenda de Melusina. ${ }^{15} \mathrm{~A}$ continuación tiene lugar la aventura que abarca casi la totalidad del libro y que está dedicada a un episodio de la vida del hada: su amor por el doncel Aiol, y el tramo que compartieron juntos, guiado por los viajes y la búsqueda de la Santa Lanza.

Sin todavía introducirnos en el resto del texto, nos interesa detenernos en la presentación que hace el hada de sí misma. Al principio nos sitúa en Lusignan, donde Melusina, que se nos revela como narradora recién en la sexta página, explica:

Me eché a dormitar — también las hadas duermen — (...) y mi antiguo sueño, el sueño de mi adolescencia famosa, escandalosa, tornó a visitarme. Pienso que debo narrarlo enseguida, para que el lector aprecie con exactitud la jerarquía excepcional de quien escribe para él. (EU:13)

El «repetido sueño» y la «historia de su vida» configuran un todo inseparable, como evidencia del cruce entre realidad y ficción que atañe a su leyenda. Ella misma señala que en las primeras páginas referirá su vida, «una anécdota harto conocida» y hace hincapié en que se trata de la vida de un hada y que quien no crea en las hadas, aún está a tiempo de dejar el libro. ${ }^{16}$

La leyenda de Melusina, muy sintéticamente, cuenta cómo el hada traba vínculo amoroso con un mortal, Raimondín, y abandona su mundo feérico para vivir con él. A pesar de que ella solicita el cumplimiento de un pacto (esto es, no verla los sábados durante su baño), ${ }^{17}$ el humano lo rompe: la espía y descubre su transformación en un cuerpo parcialmente ofidio. La visión 
desemboca en la huida de Melusina, que partirá solo para volver esporádicamente a su castillo y con sus hijos.

Hacia 1393, Jean d'Arras termina de componer Mélusine ou La Noble Histoire de Lusignan, tomando como base las tradiciones orales de la leyenda. Habrá más versiones, pero nos interesa esta en particular porque es la que menciona Melusina al comienzo de El unicornio, cuando hace referencia a su historia, específicamente a su casamiento con Raimondín:

La boda se desarrolló soberbiamente y los festejos duraron seis días. Se ha hablado de muebles de oro y de tapices bordados con diamantes, pero esas son exageraciones de Juan de Arrás, novelista que, trazando mi historia en el siglo XIV para el duque de Berry, señor de Lusignan, juzgó discreto extremar los lujos inventados. (EU:25. El destacado es mío)

Sobre este detalle de la suntuosidad, Melusina explica que los «lujos» y las «exageraciones» estaban dentro de sus posibilidades, pero que no había querido revelar tan pronto la extensión de sus facultades (aquí se da a entender que en el texto de Jean d'Arras ese despilfarro era producto de las capacidades maravillosas del hada). Este es un claro ejemplo del ejercicio de su autoridad como narradora, característica que, como señalamos al comienzo, daría mayor verosimilitud a su versión por encima de otras:; ${ }^{18}$ Melusina corrige el texto de Jean d’Arras y denuncia su carácter inventivo. ${ }^{19}$

Si nos centramos más en las permanencias diacrónicas que en los matices diferenciales de la leyenda, de acuerdo con Harf-Lancner, en el esquema narrativo melusianiano un ser de otra naturaleza se une a un hombre. Todo es felicidad y abundancia hasta el momento de la transgresión de una interdicción, a la que previamente se impone el respeto (en el caso de Melusina lo hace, primero, ella misma a su esposo Raimondín y, en última instancia, su madre, quien originó la maldición). Siguiendo a esta autora, las hadas son personajes testigo del encuentro de dos culturas y personifican diversas representaciones de la feminidad en el imaginario medieval que conllevan una serie de imágenes aparentemente contradictorias. En su clásico Les fées au Moyen Âge, tras un extenso y pormenorizado rastreo de fuentes desde la Antigüedad clásica hasta los siglos XII y XIII, cuando se tipifica el hada medieval a la que nos referimos, y cuando los dos tipos folklóricos de la diosa amorosa y la que carga con el destino se funden en la nueva figura literaria del hada amante, Harf-Lancner distingue dos grandes tipologías feéricas: los relatos melusinianos, donde el pasaje del hada se realiza hacia el mundo de los mortales, y los morganianos, donde nos encontramos con el paso del héroe al otro mundo. En efecto, los modelos se diferencian fundamentalmente por el movimiento del mortal al mundo feérico o viceversa. Podríamos relacionar, en esta línea, la búsqueda de contacto con el mundo humano de las melusinas con cierta tendencia hacia lo social, un interés por los asuntos humanos y por dirigir sus destinos.

El encuentro entre los amantes en los relatos de Melusina tiene lugar, por lo general, en un bosque o al borde del agua; espacios con tintes maravillosos que se observan, también, cuando se cruzan por primera vez Oberón, el otro hada con fuerte presencia en El unicornio, con el humano, Huon. Ante esta restricción espacial, y en la tónica de la tendencia que mencionábamos al final del párrafo previo, son interesantes los continuos intentos por parte de Melusina, frente al mito, de humanizarse: 
Yo hubiera preferido ser el fruto de una alianza menos espectacular que la resultante de la conjunción de la corona y de la mágica varita [ascendencia coincidente con la de Oberón]: eso me hubiera permitido transitar brevemente por el mundo, como cualquier mortal, sin pena ni gloria, y no tendría que permanecer aquí para siempre. (EU:17)

Esto tiene su correlato en el tratamiento que la ficción hace de la historia, que, en cierto modo, pone en cuestionamiento la visión romántica de la Edad Media. Se insiste en que las hadas de los cuentos infantiles pertenecen a una estirpe muy diferente a la de Melusina, quizás debido a:

La descomposición de las costumbres [que] se empeñó en dorar la memoria medieval y en presentarle al futuro una retocada imagen conveniente, un tapiz ceremonioso en cuya trama multicolor las damas y los caballeros se hacen gráciles reverencias. Refiero lo que vi, oí, interpreté y deduje. Claro que preferiría narrar lo que, para el consenso público, es un dulce cuento de hadas (...) la realidad es una y otra la fábula. (EU:185-186)

Los conflictos de parentesco están desde el comienzo de la historia: la venganza de las tres hermanas sobre el rey Elinas, porque no había cumplido una promesa con su madre, es lo que provoca la reacción de su progenitora opuesta a lo que esperaban y, por supuesto, las maldiciones: «Tuve que aguardar a que Sigmund Freud apareciera en nuestro oscuro mundo para comprender, en parte, los motivos de la reacción desproporcionada de la autora de mis días, de su venganza loca que, ejercida sobre mí, apuntaba en realidad a su destino frustrado» (EU:19), dice Melusina.

Cuando al comienzo la narradora relata la condena que le sentencia su madre especifica que si su marido la veía en las condiciones conocidas «[ella] sufriría para siempre la insoportable penitencia de la inmortalidad». Son muchas las ocasiones en que se lamenta por la pérdida de su esencia humana y la penitencia inmortal; esta condición es su máxima preocupación, no solo por el impedimento de concreción amorosa. El único consuelo que parece encontrar para la eternidad es hablar de sí misma: «El día aciago en que dejemos de hablar de nosotros mismos, nos habremos quedado sin el sentido de nuestra eternidad y el mundo se derrumbará entre cenizas tristes» (EU:21).

La inmortalidad, de hecho, no garantiza la perennidad física, sino todo lo contrario: el reencuentro con su madre, que le dará el cuerpo de Melusín, despierta la reflexión: «noté (...) que el tiempo también ejercía sus estragos sobre mi progenitora inmortal, y que si yo tenía que usar gafas, mi madre había engordado y comenzaba a encorvarse» (EU:213). El deseo de Melusina de obtener un cuerpo humano para poder entrar en contacto con Aiol es parte de su búsqueda por trascender los impedimentos de su condición.

Uno de los puntos clave de El unicornio se observa en el momento bisagra en que Melusina pasa a ocupar el cuerpo de un hombre. De hecho, el esquema se repite, y cuando Melusín (es decir, Melusina en el cuerpo del humano varón) se decide a contarle su amor a Aiol, vuelve a metamorfosearse en hada. En el instante en que no puede ocultar más sus sentimientos por el doncel y se los confiesa, tiene la impresión de que las palabras que salían de sus labios eran pronunciadas por otra persona. La transgresión de la (ahora tácita) interdicción revela nuevamente la naturaleza feérica. Tras quedar Melusín inconsciente, en plena batalla de Hattin, Melusina despierta ocho meses después, vuelta hada y con Oberón a su lado, y no logra ubicar en su memoria qué 
había pasado. ${ }^{20}$ Posteriormente, regresaría a Lusignan y volvería a ser lo que había sido para, años después, escribir la historia que leemos en forma de recuerdo.

\section{Melusina y su par Oberón, atisbos morganianos en la reescritura}

Habitualmente, el hada es un personaje femenino sobrenatural, como es el caso de Melusina; pero en la novela de Mujica Lainez también contamos con Oberón. La aparición de este último tiene lugar de manera inversa a la de Melusina. El «rey de las hadas» primero es ficción, en el relato de Mercator, ${ }^{21}$ y más adelante se nos presenta como un personaje con entidad real. ${ }^{22}$ Este personaje proviene del cantar de Huon de Bordeaux (ca. 1260), donde la primera aparición del rey de las hadas coincide con la interdicción de la palabra para poder cruzar un bosque; ${ }^{23}$ interdicción que el propio Huon rompe, aunque allí las consecuencias son más positivas, al menos para el humano. ${ }^{24}$ Luego, cuando Huon lo llama mediante el olifante que el hada le había obsequiado, Oberón debe asistir a su rescate.

Como Oberón, ${ }^{25}$ Melusina se describe poseedora de gran belleza: «Era muy hermosa. Perdóname la vanidad, lector, pero ¿cómo no ceder al placer incomparable de hablar de mí misma?» (EU:20). Hablar de sí misma y tener bien conceptuado el propio linaje son preocupaciones constantes por parte de Melusina en su relato y son puntos que se encuentran desde las primeras puestas por escrito de la leyenda. Según Valerie Wilhite:

Si Jean d'Arras y después Coudrette toman el personaje del hada para componer su historia-ficción y para justificar el poderío de sus mecenas es porque la figura de Melusina les permite llegar al núcleo del problema de linaje y de sus justificaciones: el punto de vista y la interpretación de eventos o personas, que no son unidades sino híbridas. (25)

Si pensamos en linajes híbridos, un claro ejemplo es justamente el de Oberón; no solo por ser un hada sino que al tener una ascendencia mixta aúna en sí distintas tradiciones genéricas (Lacalle, 2018:4 y ss.). Este hada-enano, hijo de Morgana y Julio César, presentará una caracterización feérica morganiana, por su voluntad de retener a los humanos en su bosque, más intensificada en la narración de Mercator de El unicornio que en Huon de Bordeaux:

Los viajeros, al tanto del peligro que corrían, quisieron huir, pero Oberón los detuvo y habló con el paladín de Francia. Tan entusiasmado estaba, que le ofreció socorrerlo en cualquier alternativa, a trueque de que accediera a contestarle. Huon de Burdeos sucumbió ante la voz persuasiva, la gracia menuda del rey, su elegancia y su beldad de pequeño títere y, sin pensarlo dos veces, también le habló, lo cual lo redujo en seguida a la condición de cautivo del palacio. (EU:286-287. El destacado es mío)

En El unicornio el banquete que tenía lugar en Huon de Bordeaux, antes de que el grupo siguiera su camino, se extiende a un cautiverio. Allí, si bien Huon pasa una temporada feliz, Oberón lo libera porque siente que su egoísmo está privando al mundo de las virtudes del caballero. Luego, detalla Mercator al narrar la historia, la nostalgia hizo que Oberón se quedase encerrado en su palacio mirando a través de un espejo las proezas del paladín. Este cautiverio y los hechos posteriores que se relatan en torno al vínculo entre Huon y Oberón no están presentes en el ciclo medieval, pero sí en el texto de Mujica Lainez. En este último, Melusina dice haber conocido a Huon en la isla de 
Inis Vitrin y que su hermana lo había querido enamorar vanamente porque «el guerrero no hacía más que hablar del enano Oberón y su charla adolecía de obsesiones monótonas» (EU:288).

El agregado acento en el vínculo amoroso entre Huon y Oberón permite al autor de El unicornio realizar un paralelismo y marcar cierto matiz con respecto a la relación de Melusina con Aiol, tras haber encarnado ella en el cuerpo de un hombre y adquirir la personalidad de Melusín de Pleurs. La relación entre personas del mismo sexo, que quedaba insinuada por la toma de un cuerpo otro, en el caso de Huon y Oberón ya es más directa. ${ }^{26}$ En diálogo con el hada, el enano se lamenta:

¡Ay, Melusina! Tu dilema es, hasta cierto punto, semejante al mío. Los dos nos hemos enamorado de un imposible. Pero, si bien se mira, todo gran amor es imposible y en eso finca su grandeza. Yo, que soy un hombre-hada, tuve la desgracia, o la suerte (porque mi desgracia me ha hecho desconcertantemente feliz), de enamorarme de un hombre valiente y hermoso; tú, que eres una mujer-hada, estorbada por un cuerpo de hombre, te has enamorado de otro hombre, hermoso y valiente también. Ninguno de ellos, ni Huon de Burdeos ni Aiol de Lusignan, ha sido o será capaz de amarnos (...). Estamos condenados a la soledad. (EU:297)

Ligada a la inmortalidad, se insiste, la condena de las hadas es «esperar». Oberón entrega su cuerno a Melusina, «en atención a lo que me has narrado sobre la calma existencia que lleva mi amado en Inis Vitrin. Ahora dormiré tranquilo» (EU:299), y se despiden. La reflexión que acabamos de citar en boca de Oberón tiene su contraparte, una vez que se separan, a cargo de Melusina:

Él era un hombre prendado de otro, y si bien con los menoscabos y las proyecciones que se inferían de su degradación de enano y de su enaltecimiento de espíritu, de pudiente hijo del sortilegio, no hay duda de que poseía el equilibrio propio de un hombre cabal, en tanto que yo, víctima patética de otro hombre, era hombre por fuera y mujer por dentro, en la raíz de mi naturaleza, lo cual suscitaba en mí una inestabilidad que mi preeminencia fantástica no conseguía contrarrestar. (EU:300)

De acuerdo con el texto de Mujica Lainez, Presina, madre de la protagonista, también había sido la encargada de la maldición arrojada sobre Oberón en su nacimiento. En Huon de Bordeaux y Le roman d'Auberon (precuela fechada a comienzos del siglo XIV) se mencionan varias hadas que otorgan los distintos dones, pero en ningún lugar se precisa el nombre de Presina. Vemos aquí un nuevo movimiento por parte del autor de El unicornio para emparejar a los dos personajes feéricos.

Por un lado, y como detallábamos en nuestra vigésimo primera nota, los oyentes del relato que narra Mercator se quedan con las posibilidades que brindarían los objetos maravillosos de Oberón (es decir, se posicionan en el rol que ocupa Huon en el cantar). Por otro lado, cuando Melusina conversa con el hada-enano en persona, el interés sobre su historia, en cambio, radica en la empatía que genera la imposibilidad compartida de concreción del deseo.

\section{Interdicciones feéricas}

Las hadas viven a medio camino entre dos mundos, en sitios fronterizos. En el relato de Jean d'Arras, cuando el hada se casa con el mortal, el futuro esposo debe aceptar una condición en forma de interdicción. Esa interdicción, en las distintas variantes feéricas, puede estar relacionada con la vista (como presenciar la desnudez del hada), o con hacer una pregunta (como sucede 
con Oberón, o en muchas de las versiones de la historia de Melusina, con la interrogación por su linaje). $\mathrm{Al}$ ser violado el pacto se produce el término de la felicidad. Esta violación representa, en cierto modo, la imposibilidad del contacto definitivo entre ambos mundos y la incapacidad por parte del hada de integrarse al mundo humano, como era su voluntad. Se imponen el silencio, en el bosque de Oberón, y la restricción de la visión, a partir de la maldición de Melusina, por medio de un secreto, un tabú. Quebrar la prohibición revela la naturaleza feérica a los humanos. Esta revelación desemboca en la huida o en la separación que, al fin de cuentas, es producto de la incomprensión, la falta de confianza y la obediencia humanas. Pareciera, y esto es más explícito en Huon, que existe cierto matiz de incitación por parte del hada para que el mortal viole el pacto. Primeramente, Oberón tienta a Huon y a sus hombres a quebrar el silencio cuando ingresan al bosque $^{27}$ (para que, en un gesto más morganiano, queden atrapados en su mundo ${ }^{28} \mathrm{y}$, luego, lo censura ante el llamado innecesario por medio del tañido del olifante. Por otra parte, un último detalle que se agrega en las narraciones melusinanas, en relación con la ruptura del pacto, es que en algunas variantes la visión sabatina no produce la ruptura (como sí sucede en la versión de $E l$ unicornio), sino su comunicación yverbalización posteriores (Harf-Lancner:105 y ss.).

Esta inadecuación irremediable entre dos universos ${ }^{29}$ tiene su correspondencia en la imposibilidad del deseo. Al mismo tiempo, y con eco en la construcción de la alteridad, el respeto de la interdicción podría pensarse como la posibilidad de aceptar al otro tal como es sin preocuparse por las extrañezas de su conducta. En el caso de Melusina, la desaparición está unida a la revelación de su verdadera naturaleza y se liga, también, a la condición monstruosa y al tabú de la desnudez.

En los relatos morganianos la interdicción no tiene que ver con la naturaleza del hada sino con la desobediencia y la nostalgia que quiebran el olvido. El mortal que penetra en el mundo sobrenatural olvida por un tiempo todo lo que precedió a esa existencia y, cuando retorna al mundo humano, toma conciencia del tiempo que ha transcurrido. Se vuelve a la temporalidad de los hombres y se muere de vejez repentina. Así, se invierte la condena inmortal, del hada al humano. La intrusión de un extranjero en un mundo que no le pertenece, tanto de un lado como del otro, pareciera estar en el meollo del problema. He allí el trasfondo de la interdicción.

A diferencia de estas hadas, que retienen a su amante en contra de su deseo, en la novela argentina Melusina y Oberón no pueden concretar sus anhelos. ${ }^{30}$ No se nos cuenta ya la historia de Melusina con Raimondín, sino con Aiol. Y, en el caso de Oberón, se agrega un romance entre el hada y Huon, inexistente en el ciclo medieval y, también, unidireccional. Como señalábamos en el apartado anterior, esto resalta las similitudes entre la situación de ambas hadas. La imposibilidad de concreción amorosa, entonces, es consecuencia del incumplimiento, por parte de los humanos, y de la imposición de las interdicciones, por parte de seres feéricos, que separan dos mundos diversos. No solo se carga con dicha imposibilidad, sino que además, tanto Melusina como Oberón deben esperar en soledad a lo largo de su vida inmortal.

El esquema narrativo melusiniano, resignificado a lo largo de los siglos en versiones tan diversas como el film Shrek, o variantes recientes de La bella y la bestia, ${ }^{31}$ en El unicornio es tematizado especialmente por la imposibilidad de concreción y la prohibición de la unión entre un hada y un mortal. En las dos versiones medievales de Melusina, no es sino cuando Raimondín declara haber visto al hada en el momento prohibido que se acaba la felicidad. Es decir, cuando el episodio es contado. Por haber sido observada cuando no debía serlo, Melusina resulta condenada, en el texto de Mujica Lainez, a no poder ser nunca vista por ningún otro ser humano; ${ }^{32}$ esto incluye, 
por supuesto, a su nuevo amado, Aiol. Esta imposibilidad de concreción ronda a lo largo de toda la novela y se replica y destaca en otras intertextualidades. ${ }^{33}$

La insistencia en la pérdida de la noción del tiempo en la Edad Media, la falta de apuro y la creencia de que la vida infinita aguardaba luego de la muerte, así como también el recuerdo de las muertes que la van acompañando acentúan la maldición de la que es presa Melusina. Sus besos no son más que soplos, sus manos no pueden detener la caída al vacío del constructor Pons. ${ }^{34} \mathrm{El}$ contacto más cercano que logra con Aiol se da durante el lapso en que participa de sus sueños y recuerdos, incluso, cerciorándose de su propia aparición en la mente del muchacho. Esa imagen, un modo de asomarse a la vista del reflejo, se replica en la escultura que inicia Pons y en la que talla en madera Aiol en la ermita de Lussac, ambas obras descriptas en el tercer capítulo «En la ermita de Lussac». Pareciera que solo narrando lo que ya vivió desde una época lejana, su único refugio, puede eludir su mayor tortura: «ir por el mundo eternamente, remedando gestos pasados, como si cuanto yo hago fuera sombra, reflejo, recuerdo y espejismo y no lograra concretarse» (EU:114); por eso la importancia, casi frenética, de resaltar que su versión de los hechos siempre es la verdadera. Su inmaterialidad, producto de su inmortalidad, le impide intervenir en las acciones del presente de su vida, pero le posibilita reconstruir continuamente su propio pasado. Las condenas que pesan sobre los personajes feéricos los acompañarán, con su inmortalidad, hasta el presente de nuestros días.

En relación con el afán por escribir sobre el pasado como necesidad para comprender la experiencia personal y colectiva, algunos críticos que se dedicaron a trabajar la novela vinculan los comentarios metanarrativos con interpretaciones biográficas basadas en los testimonios del propio Mujica Lainez y el contexto represivo predictatorial argentino (Peralta). ${ }^{35}$ Específicamente, se detienen en cómo Mujica Lainez haría uso de la leyenda de Melusina para canalizar la prohibición y la censura de la época sobre los vínculos homosexuales. ${ }^{36}$ Jorge Luis Peralta señala que los disfraces son un motivo recurrente en la novela, así como también los momentos de revelación de identidades «verdaderas» de distintos personajes, cuyo nombre o apariencia se habían ocultado a otros. Peralta vincula esto con la posibilidad de canalizar cierta denuncia hacia la represión de la homosexualidad y «articular posibilidades eróticas que escapaban a la rígida moral dominante en la Argentina de mediados de la década de 1960» (199-200). Estos gestos de subversión en un contexto hostil a la diversidad, de todos modos, nunca llegan a concretarse (tampoco en los casos de Aymé con Aiol u Oberón con Huon). Por nuestra parte, consideramos que el trabajo con la homosexualidad es velado, en los vínculos Melusín-Aiol y Melusín-Agnès, y levemente más visible, en el lazo Huon-Oberón. No obstante se logra cierto efecto de extrañamiento, sobre todo en el quinto capítulo, «Un cuerpo para Melusina», cuando para que pueda cumplir su voluntad de tener contacto físico con Aiol, y cansada de ser invisible para los humanos, Melusina recibe de su madre el cuerpo de un joven. Ella misma se presentará como Melusín de Pleurs. Esto permite colocar descripciones de deseo del cuerpo masculino desde el punto de vista de un varón y divagar sobre la ambigüedad y la labilidad de las identidades. ${ }^{37}$

\section{A modo de conclusión}

En El unicornio se resignifica toda una serie de elementos del imaginario medieval, entre los que destaca el rol de las hadas. En este trabajo nos hemos abocado al tratamiento y la construcción que reciben Melusina, narradora y protagonista, y Oberón, personaje secundario pero clave de la 
novela. Su funcionalidad primordial ya no es ser parte de la justificación de un linaje ni brindar objetos maravillosos que ayuden a completar la tarea y el recorrido iniciático de un héroe. Aquí, el espacio central está dedicado a las imposibilidades de concreción física amorosa, tratadas, además, desde el punto de vista de las propias hadas que las padecen.

Recapitulando brevemente, en este artículo intentamos trazar un panorama de la caracterización que recibe Melusina en la novela argentina de Manuel Mujica Lainez en lo que atañe, especialmente, a su naturaleza feérica. Ante esto aparecieron constantes que llevan al sufrimiento continuo, como la inmortalidad y la intangibilidad. El deseo de romper con ese padecimiento, con el objetivo de concretar su amor por Aiol, lleva al hada a ocupar un cuerpo humano masculino. Frente a este caso, nos dedicamos a analizar el rol de Oberón en la novela, como par contrastante de Melusina, teniendo en el horizonte su singularidad en la textualidad medieval para relevar comparativamente los rasgos distintivos de la reelaboración del siglo XX. En el tercer apartado vimos que la pena compartida por ambos personajes era la imposibilidad de concreción del deseo por sujetos amados, línea narrativa no desarrollada en ninguna de las variantes medievales de los relatos. Esta imposibilidad se puede observar, y por ello las hadas resultan personajes idóneos para canalizarla, como intentamos demostrar, a través de las prohibiciones sensoriales. Los propios seres feéricos padecen las interdicciones que los rodean y la soledad se hace eterna. El tono ya no es épico, maravilloso, ni aventurero sino trágico. Por consiguiente, penetrar en un mundo otro o metamorfosearse son alternativas problematizadas fuertemente en esta ficción.

La distancia temporal y espacial podría favorecer el tratamiento de cierta heterodoxia sexual y de género. Por ello, quizás, la ambientación medieval predispone en contextos adversos discusiones que son vistas como dificultosas, incómodas o, incluso, peligrosas. En este sentido, creemos que la condena a la inmortalidad y a no poder amar es un reflejo de la permanencia histórica de ciertos condicionamientos socioculturales, que se manifiesta en las prohibiciones sensoriales en torno a los personajes híbridos y feéricos. Esta consideración, que observamos escuetamente a través de este recorrido por el caso particular de El unicornio, podría hacerse extensiva hacia gestos de otras textualidades que trabajan desde el medievalismo, recuperando personajes y episodios del imaginario medieval para repensar situaciones del presente, sea por oposición o por semejanza.

\section{Notas}

1 Agradezco los comentarios y las sugerencias bibliográficas de los/as referatistas dado que han resultado muy valiosos, tanto para la mejora de este trabajo en particular como para la continuación de mi investigación en esta línea.

2 Si bien se suele utilizar el término «temática» para referir al período de las novelas históricas, cabe aclarar que con ello nos referimos a la época que sirve de escenario y ambientación para la trama, cuyos imaginarios y acervos literario e histórico son el puntapié de la ficción. Para un primer acercamiento teórico al subgénero, los remitimos a Lacalle (2019).

3 Mujica Lainez también trabaja con la Edad Media en otros textos como Crónicas reales (1967) y El escarabajo (1982), aunque carecen del cariz histórico que caracteriza a El unicornio (de hecho, estas últimas han sido descriptas como «novelas antihistóricas»). Dos detalles sobre el autor que serán relevantes y resonarán en este trabajo: por un lado, el lugar prominente que la escritura de biografías ocupa en su obra (se dedicó a las vidas de Miguel Cané, Hilario Ascasubi y Estanislao del Campo), y, por otro lado, sus lazos con París (ciudad donde pasóvarias estancias, completó su educación primaria y se desempeñó políticamente en un cargo de relaciones internacionales). Para profundizar en el aspecto contextual y biográfico del autor resultan invaluables, 
aunque con un sesgo relativamente parcial por la cercanía y el enfoque por momentos de anecdotario compartido, los textos de Jorge Cruz y Oscar Hermes Villordo, ambos colegas y amigos de Mujica Lainez, y las «conversaciones» con María Esther Vázquez. Para ejemplificar, recordemos la escena que se nos ofrece como dedicatoria en El unicornio, quizás con un matiz de planificación o impostación autoral mitificadora, que reconstruye el momento fundacional en que surgiría la idea para la redacción de la novela, cuando Mujica le confía el proyecto en Rodas a Ricardo González Benegas (Vázquez:99): «en mayo de 1960, en la isla de Rodas, habla por primera vez a su amigo Ricardo González Benegas de El unicornio» (Cruz:148); y «Aún no había concluido la redacción de Bomarzo y ya pensaba en su próxima novela. En Rodas le habló a Luzbel de El unicornio (dedicado a él y a su amiga Ersi Hatzimihali)» (Villordo:221). Cabe decir que dedicamos este espacio, si bien en nota pero importante en extensión, al costado biográfico ya que coincidimos en la relevancia de aserciones como: "Acaso El unicornio sea el libro en que su autor se refleja con mayor autenticidad y en el cual podrían rastrearse elementos profundamente autobiográficos» (Cruz:149). En este sentido, Cruz destaca la constancia y el valor temático en la obra del escritor de los antepasados y los linajes, desde su llegada al territorio argentino en el siglo XVIII, y realiza una detallada genealogía de las dos ramas familiares (y sus vínculos con, entre otros, los Cané y los Varela) que confluyen en el autor.

4 En parte por la censurada y prohibida trasposición operística (también de 1965) a cargo de Alberto Ginastera (1916-1983).

5 Este conjunto se contrapondría a la obra más temprana del autor, cuyas narraciones se sitúan en el ámbito porteño argentino. Este vaivén podría tener un correlato en las otras dos grandes ramas laborales del escritor, la periodística (más ligada al espacio local) y la museística (que lo conecta con el territorio europeo). Con la primera de las novelas que conforman el «tríptico», Bomarzo, Abate postula una bisagra entre dos grandes partes de la obra de Manuel Mujica Lainez: dos conjuntos de 25 años, con 12 y 13 volúmenes publicados, respectivamente, en cada etapa. Es, además, casi excluyente en su composición, la partición entre un primer momento dedicado a la escenificación histórica en Buenos Aires, y una segunda etapa abocada al pasado universal (27).

6 La redacción de los cuadernos de notas de El unicornio comienza en noviembre de 1961 y finaliza en abril de 1964, cuando Mujica entra en la fase de escritura de la novela, que tomará un año. Una de las mayores preocupaciones que manifiesta el autor es la complejidad de compaginación de materiales de distinta procedencia (fundamentalmente, la legendaria y la histórica) en un entramado discursivo coherente; en palabras de Abate, una «búsqueda creativa del montaje» (106).

7 En Los ídolos (1953) el propio Mujica denomina «flaubertismo» a esta voracidad por documentarse, por el rigor bibliográfico y por la reconstrucción arqueológica de las épocas evocadas (Cruz:148). Sobre la novela que nos atañe en particular, Jorge Cruz detalla: «En 1963, enfermo de hepatitis, se ve obligado a permanecer en cama más de tres meses. Durante ese período, que el escritor ha calificado de singular y extraño, lee muchos libros sobre temas medievales, relacionados con la novela que prepara, El unicornio...» (145).

8 Sandro Abate postula que en la novela la historia se encuentra en un segundo plano, casi como telón de fondo: «El unicornio, por su parte, es producto de la articulación de dos componentes heterogéneos que operan en el texto simultáneamente (una historia legendaria y una selección de acontecimientos históricos medievales) (...) una propuesta narrativa que familiariza al texto con las coordenadas del relato maravilloso, propio de los cuentos de hadas, apenas muy tenuemente contaminadas por el distanciamiento referencial que conlleva la instancia enunciativa a modo de memorias» (19y 20). El foco es, más bien, el desarrollo poético de la ficción, cuya acción es casi en su totalidad fruto de su propia invención (18).

9 En este trabajo se emplearán las siguientes siglas: $E U=E l$ unicornio, $H B=$ Huon de Bordeaux y $R A=$ Le roman d'Auberon. Las referencias corresponden a las ediciones listadas en la sección de bibliografía al final del artículo.

10 Basten dos ejemplos ilustrativos: «La mayoría de los grandes personajes de la naciente literatura fueron hijos de reyes (...) lo destaca Proust» y «Vivíamos en la Edad Media; lo insólito se revestía de bendita naturalidad; nuestros contemporáneos (como los actuales, pues todo es cuestión de costumbre, que con igual llaneza no se pasman ante la perspectiva de viajar a la Luna) intimaban con la pirotecnia de los prodigios» (EU:16 y 27).

11 En el ámbito nacional la labor es más incipiente y, dado que nuestro foco principal en esta ocasión no es el desarrollo del medievalismo en Argentina, solo mencionaremos a modo de ejemplificación la reciente edición del Lancelot y Elaine de Tennyson (Artal). 
12 Resulta interesante contrastar el uso de la Edad Media que se observa en El unicornio con las concepciones que regían en el siglo XIX, tras la independencia del Río de La Plata en 1816 (pro y anti «Leyenda negra»): «The reformers in particular considered that their newly politically independent societies were largely still living in a medieval period that had been established with the Spanish conquest» (Altschul:152). Quizás, aquí se perciba, en parte, el germen de uno de los motivos de emplear el reservorio medieval del imaginario francés y no el hispánico, como podría parecer más natural por la lengua. Esto limitaría la producción de novelas como la estudiada a una cierta elite que tenía acceso al conocimiento linguíistico necesario (que, además, por entonces estaba mucho menos extendido al grueso de la sociedad que ahora, y las traducciones eran sumamente escasas).

13 En su Genio y figura de Manuel Mujica Lainez, Jorge Cruz destaca en varias oportunidades que la inmortalidad fue uno de los temas que más obsesionó al autor a lo largo de toda su narrativa (163).

14 Esta estructura podría pensarse en dos grandes partes, con una división mayor de acuerdo con los escenarios donde transcurre la acción: Francia y Tierra Santa. Desde una óptica general, percibimos una alteración hacia la segunda mitad del libro, cuando se narra la expedición a Tierra Santa, donde la fuerte presencia de la primera persona se difumina un poco y cede espacio al racconto de los hechos históricos. La proliferación onomástica de personajes, lugares e intrigas políticas conforma una reconstrucción contextual pormenorizada que pone en juego el conocimiento del trasfondo histórico por parte del autor y exige, hasta cierto punto, un lector erudito. Esta partición y el terreno ganado por la historia encuentran su equilibrio hacia el cierre mediante la inclusión del personaje de Oberón: «Lo legendario pierde la entidad literaria que había tenido al inicio del libro, salvo en lo relativo al cuerno de Oberón» (Abate:121).

15 En relación con las fuentes que tomó Mujica Lainez para este relato, Abate explica: «Su historia será narrada, a modo de un cuento intercalado, en el capítulo I de la novela, siguiendo casi al pie de la letra la versión de la leyenda que proporciona François Eygun en su libro Ce qu'on peut savoir de Mélusine et de son iconographie (Poitiers, 1951), cuyas 43 páginas habían sido leídas y profusamente anotadas con apuntes marginales, por el mismo Mujica Lainez» (115). Seguidamente, Abate presenta, a modo argumentativo, un cuadro comparativo entre pasajes de ambos textos. En cuanto a la documentación empleada para el trabajo con las hadas se destaca el Quand les fées vivaient en France (París: Hachette, 1923), de Ivonne Astorga, que figura reseñado en el quinto cuaderno de notas (de allí se toman las fuentes de Oberón).

16 Esta advertencia sirve a Melusina para tildar las posturas que proliferan en su presente de «escepticismo anticuado»y "pobreza de espíritu», ante todo lo que sucede en el mundo y es inexplicable porque funciona por razones que se nos escapan. Estos posicionamientos, según Melusina, nos privarían de enterarnos de asuntos de interés trascendente.

17 Oscar Villordo relata una anécdota de 1964 durante la «Fiesta de las Letras» en Necochea (ciudad costera al sur de la provincia de Buenos Aires). Allí es invitado Mujica Lainez, quien va acompañado por Carlos Bruchmann. El episodio parte de un encuentro con su amigo José Luis Lanuza, cuando este último ingresa a la habitación de Mujica en el hotel y ve la puerta del baño entreabierta y en la bañadera a Bruchamnn. «Años después, cuando el Peque [Lanuza], atento e incansable lector, descubrió en El unicornio la escena de Aiol desnudo en la tina de agua tibia (en compañía del hada Melusina, invisible para la ocasión), la unió en seguida a la vista en el Hotel de Necochea [esta escena no corresponde a la del relato de la leyenda al comienzo, aunque sí es un claro juego con ella, sino al cuarto capítulo (EU:151)]. Lo comentó entre sus amigos, sin estar seguro de que fuera así. En lo que no se equivocaba era en el modelo: Aiol era Bruchmann» (233). Otro relato interesante en relación con los baños se desprende de la sospecha de intoxicación devenida en hepatitis que padecía Mujica Lainez, que Villordo adjudica al viaje a Panamá de 1964: «El estado calamitoso de las manos ha hecho que El unicornio quedara detenido en el capítulo quinto. Pudo retomar la redacción pero al aproximarse al final del libro debía hundirlas en agua caliente cada hora para que el alivio del baño de inmersión le permitiera seguir usando la pluma» (251).

18 En el segundo cuaderno, que lleva por título «Notas sobre la Edad Media. Cuaderno de bocetos para una novela», en una entrada fechada el 31 de diciembre de 1962, se menciona por primera vez la idea de que el hada Melusina fuera la narradora de la novela: «Yo encuentro el manuscrito en la extraña librería invisible cercana del Museo Botánico [este tópico común en las novelas históricas del "manuscrito encontrado", por supuesto, luego fue desechado]. Es una copia del siglo XVI o del XVII o quizás del XIX. No se puede saber, dado lo extraño de la caligrafía. Me cuesta mucho leerlo, transcribirlo, adaptarlo. 
Comenzar refiriendo ese hallazgo. El manuscrito empieza con el relato de los amores del hada y el señor de Lusignan» (Abate:108). La primera mención del hada en los cuadernos se observa solo quince días antes y se relaciona con los ojos de distintos colores de Guy, el mayor de sus hijos, particularidad que heredará Aiol.

19 Esta operación también puede observarse en el caso de la más extensa variante de la leyenda del corazón comido, que se desarrolla en el capítulo cuarto, «El devorado corazón»: «Le han adjudicado diversamente la anécdota al arpista Guirón y al sire Coucy, sin dejarle a Guilhem, el verdadero inmolado, ni siquiera el pavoroso privilegio de la exclusividad» $\mathrm{y}$ «Cualquiera que haya leído algo sobre las vidas de los trovadores, recordará el caso celebérrimo. Pero esas biografías suelen fundarse en anécdotas apócrifas» (EU:189 y 173). Esto es explicado por Melusina cuando se dispone a profundizar en las intrigas amorosas que llevaron al desenlace de la leyenda (que, por supuesto, ella también conoce de primera mano por haber oído confesiones y haber presenciado los acontecimientos). Lo interesante de estos ejemplos es que se pone el énfasis en el problema del grado de verosimilitud cuando en la novela se presentan narraciones medievales que tienen variedad de versiones y cierto lazo con cuestiones más cercanas a la oralidad. Por otra parte, aquí también se reformula el relato medieval, con una complejidad psicológica mayor de los personajes involucrados (a pesar de las mentadas coincidencias con la versión del Decamerón) para tematizar el amor homosexual de Aymé por Aiol y la mutación del primero en lobo (cf. Abate149).

$20 \mathrm{El}$ polo opuesto de la memoria es el olvido, que paradójicamente también puede crear una «nueva verdad». Esta temática se observa desarrollada de una manera muy interesante en una novela histórica medieval, The Buried Giant (2015), de Kazuo Ishiguro. Allí, en un mundo posartúrico, un hechizo en forma de niebla, sostenido por la vida de un dragón, hace que la gente pierda sus recuerdos. Este efecto había sido pensado por el propio Merlín para comenzar un nuevo mundo sin el resentimiento o enemistad entre sajones y britanos.

21 El juglar, que desde un principio se había sumado al grupo de Aiol, «[Mercator] requirió el permiso de Baudoin para referir la historia del enano Oberón y de Huon de Burdeos, y aunque se deducía fácilmente que la archirrecordaban casi todos, aumentó la algazara y el rey alzó su guante púrpura en signo de aprobación. Silbó Mercator dos o tres veces y le respondió el mirlo, originándose un contrapunto entre la zanfonía y el pájaro, hasta que Mercator inició el relato cadencioso, mecido por las rimas» (EU:284). Luego de esta introducción se da inicio a la narración que continúa hasta la página 289, interrumpida por reflexiones de los personajes como, por ejemplo: «No nos vendría mal ese cuerno, en las actuales circunstancias», por parte de Felipe de Flandes, $\mathrm{o}$ «Si yo hubiera tenido a mi lado un hada o un personaje como Oberón (...) mi vida no sería tan difícil», por parte de Aiol (EU:287 y 289).

22 Esto ocurre en el último capítulo de El unicornio, titulado «El cuerno de Oberón». Llamativamente, en la edición inglesa de 1983, la traducción de Mary Fitton le quita el peso literario al reemplazarlo por «The Horns of Hattin», en alusión a la batalla. Por su parte, Melusina primero es una narradora con entidad real al interior de la novela y, recién después, cuenta (con las aclaraciones que considera necesarias) su leyenda, y remite a la versión literaria de Jean d'Arras.

23 Para recuperar su feudo, Huon, par de Carlomagno, debe conseguir la barba y cuatro dientes del emir de Babilonia, entre otras tareas; en esa travesía se cruza con Oberón. Gériaume advierte a Huon antes de que atraviesen el bosque: «Dentro de él [el bosque] vive un enano, es la verdad, que, aunque apenas mide tres pies de estatura, es más hermoso que el sol en verano. El nombre que le viene por derecho es el de Oberón. Todo el que entre en el bosque y le dirija la palabra se quedará dentro de él» (HB:98). Para profundizar en este episodio, véase Lacalle (2014).

24 Tras devolverle el saludo y decidir hablar con el hadaenano, además de atravesar el bosque con sus acompañantes sanos y salvos, Huon recibe de Oberón dos objetos maravillosos y todos son invitados a un gran banquete. Oberón especifica que le otorga los dones porque «A causa de tu gran lealtad te amo más que a nadie nacido de mujer» (HB:105), y le cuenta su historia y su linaje. Los dos objetos que recibe Huon, con la condición de que no mienta y mantenga su lealtad, son un cáliz que se llena de vino especiado si es sostenido por alguien justo, «Por el amor que te tengo, te entregaré este preciado cáliz» (HB:109), y un cuerno: «Has de saber que cuando toques este cuerno de claro marfil, yo lo oiré desde mi ciudad de Monmur, por lejos que te encuentres, y, acompañado de cien mil hombres armados, acudiré a defenderte de tus enemigos» (HB:109).

25 Gériaume anticipa la descripción en Huon de Bordeaux que citamos más extensamente en la nota vigésimo tercera: «es más hermoso que el sol en verano» (HB:98). Por otra parte, el propio Oberón y un narrador en tercera persona, que cuenta su genealogía en la precuela fechada en 1311, relatan los dones de 
las hadas durante su nacimiento, entre los que se encuentra el detalle de la belleza descomunal: «Cuando el hada vio lo que me había hecho [convertirlo en enano giboso y que dejara de crecer a los tres años], quiso reparar el daño y me dio el don que ahora os diré: después del Señor sería el hombre más bello que jamás existiera. De hecho, tal y como veis, soy tan bello como el sol en verano» (HB:105); «La tierce fee adont le resgarda/ Puis dist en haut: "Mal ait qui ce pensa/ En son despit! Soushait que l'enfes ja/ Puis que d'eage .XV. ans passés ara/ Ja puis cel di, jamais n'enviellira/ Ne jamais jour, plus biax ne naistera"» (RA, 1973, vv. 1400-1405:65).

26 Oscar Villordo dedica en su biografía un buen espacio al tema de la sexualidad: «Manuchito tenía quince años y comenzaría para él, también, otro tipo de enseñanza (...) la aventura del sexo. Conviene decir que este aspecto de su experiencia nunca quedó del todo claro. Hay, sin embargo, expresiones del propio Manucho que hacen pensar que fueron ambiguas y tuvieron que ver con el maestro [John Light, preceptor de inglés durante su estadía en Londres]» (61). Esta aserción, en conjunción con el episodio del baño referido en la nota 17, es el momento más nítido en que se alude a la homosexualidad (o bisexualidad; está claro que en la época de Mujica Lainez, e incluso durante la publicación de los tres libros biográficos, estos eran temas mayormente tabús).

27 En el primer encuentro de Huon y sus hombres con Oberón, el hada solicita: «En el nombre del Rey del Mundo saludo a los catorce compañeros que andan por mi bosque. Por el óleo, por el crisma del bautismo, por la sal y por todo lo que Dios ha hecho y ha creado, os conjuro, en el nombre de Dios de Majestad, a que me devolváis el saludo» (HB:100). Antes de ello, y haciendo sonar su cuerno, los hace cantar de manera mecánica.

28 En El unicornio se pone el énfasis en el carácter de maldición de la interdicción que pesa sobre Oberón: «La desgracia no se separaba del enano vestido de verde. Ni siquiera en esa floresta remota, sobre la cual soplaban los vientos que empolvaban los árboles con las arenas de los desiertos cálidos, consiguió hallar Oberón la tranquilidad perseguida. Un embrujo incómodo, posiblemente armenio, estableció que los que contestaran al enano, si éste les dirigía la palabra, caerían bajo su poder, prisioneros, aunque Oberón no lo quisiera» (EU:285-286. Los destacados son míos). Este tono negativo para el propio hada no se encuentra presente en Huon de Bordeaux.

29 La propia Melusina reflexiona cuando llega al momento de la escena en que Raimondín la ve metamorfoseada: «A esta altura de nuestra relación se produjo la gran escena del cuento de hadas. Los contactos de las hadas y los hombres, si bien a menudo atractivos, suelen volverse difíciles. Díganlo si no las complicaciones del vínculo del doncel Lanval con su hada bonita; las de Gauvain con Morgana; las de Morgana con el gigante Rainouart (...); las de Arma con Marc Pen Ru (...); las de Madoine con el caballero Laris (...); las del paladín Guingamor, que pasó tres días en el palacio de las hadas (...). ¡Y yo misma, yo misma, que ofrezco quizás el ejemplo más trágico!» (EU:30-31).

30 Hay que tener en cuenta, además, que en Oberón se tamiza la figura feérica mediante el cristianismo: el hada-enano tiene un lugar reservado a la derecha de Dios y, en última instancia, sus poderes provienen de la divinidad cristiana. Cuando se describen los dones que recibe al nacer se explica: «[el hada número cuatro] concedió aún más: conocer todos los secretos del Paraíso y escuchar el canto de los ángeles que están en lo alto del Cielo; el no envejecer nunca y, finalmente, tras decidir yo mismo la hora de mi muerte, el sentarme en el trono que Dios me reserva a su lado» (HB:106). En relación con la hibridez de Oberón y su valor sincrético, conviene aquí, para notar la diferencia, recordar cómo Melusina caracteriza a Balduino IV en El unicornio: «Se argumentará que la opinión de un hada, en lo que a asuntos místicos concierne, vale poco, pero es bueno que el lector tenga en cuenta que yo he sido testigo de los hechos que narro y que mi testimonio directo, único en la actualidad, revista una trascendencia indiscutible» (EU:366-367).

31 Se entiende aquí que la resignificación en los ejemplos fílmicos mencionados alude a las diversas funcionalidades narrativas de la revelación de la verdadera naturaleza de un ser aparentemente monstruoso. En el primer caso se trata, por supuesto, de la princesa Fiona y en el segundo de la Bestia.

32 De manera opuesta, se espera que el amado atienda todos sus sentidos y dirija toda la atención a su amante. En el relato que se hace de la leyenda al comienzo de El unicornio se cuenta que cuando un amigo de Raimondín lo alienta para que vaya a ver qué hace su mujer los sábados, él no sigue su consejo; según Melusina «mi esposo no le prestó oídos. No tenía oídos, lengua, brazos y demás, sino para mí» (EU:26).

33 Por tomar un ejemplo diverso, en el episodio del «devorado corazón» se deja bien claro que Guilhem de Cabestanh nunca consuma su amor por Seramunda. Además, tras el episodio del corazón comido, Azelaís e Ithier pierden el habla por un 
largo tiempo. En el caso de Ithier, la palabra se recupera con la confesión, seguida por la muerte.

34 A partir de estos episodios, Villordo refiere el patetismo del rol del hada y, agrega, «su angustia recuerda la condición dolorosa del amor homosexual, la de no poder comunicarse plenamente con el otro, ya que la atracción ocurre casi siempre con un heterosexual» (256).

35 Valerie Wilhite, por ejemplo, propone un paralelismo entre la hibridez identitaria de los personajes feéricos y la del propio Mujica Lainez, un miembro de la oligarquía terrateniente que uniría la ruralidad y la cultura de la ciudad, cuya vida se desarrolla a caballo entre Francia y Argentina, y que también estaba en búsqueda de su propia identidad como escritor. Por su parte, Guadalupe Fernández Ariza, en línea con la esencia híbrida y la imagen de dualidad de las figuras feéricas, plantea que el "ser ambiguo», como se caracteriza al unicornio y a las hadas, posibilita reflexiones sobre la construcción del yo y de la identidad; una estructura en la que subyacen el mito de Narciso y la autocontemplación.

36 Cuando María Esther Vázquez le pregunta a Mujica Lainez específicamente sobre este punto, y sobre la asunción de Jorge Cruz en relación con la presencia de rasgos autobiográficos en la novela, Manucho responde: «Puede ser. Los críticos ven cosas tan curiosas... Puede ser si uno se pone a interpretar en el sentido de que, como Orlando para Virignia Woolf, el hada Melusina para mí, al cambiar de sexo, permite mirar todo desde ángulos distintos; como consecuencia, puede ser que psicológicamente se parezca a mí. Pero yo no soy un hada» (100). A continuación se reconoce, también, en la complejidad y timidez de Aiol.

37 Por su parte, Sandro Abate coincide con este planteo: «Melusín/Melusina, entonces, sufre la desdicha de no poder consumar ese amor, que ahora se ha tornado homosexual, y de encontrarse además en un hermoso cuerpo masculino que la coloca en la situación de ser asediada por otras mujeres» (94).

\section{Referencias bibliográficas}

Abate, S. (2004). El tríptico esquivo. Manuel Mujica Lainez en su laberinto. Bahía Blanca: Editorial de la Universidad Nacional del Sur.

Altschul, N. (2016). Medievalism in Spanish America after independence. En D'Arcens, L. (Ed.). The Cambridge Companion to Medievalism. Cambridge: Cambridge University Press, 151-164.

Artal S. (Ed.). (2018). Alfred, Lord Tennyson. Lanceloty Elaine. Buenos Aires: Dedalus.

Cruz, J. (1996) [1977]. Genio y figura de Manuel Mujica Lainez. Buenos Aires: Eudeba.

D’Arcens, L. (Ed.). (2016). The Cambridge Companion to Medievalism. Cambridge: Cambridge University Press.

Fernández Ariza, G. (1992). El unicornio de Manuel Mujica Lainez: tradición literaria y constantes genéricas. Revista Iberoamericana, LVIII(159), 407-421. https://doi.org/10.5195/reviberoamer.1992.504

Harf-Lancner, L. (1984). Les fées au Moyen Âge. Morgane et Mélusine. La naissance des fées. Paris: Honoré Champion.

Lacalle, J.M. (2014). «Ciert tout fantomme quant que vous y vairez»: aproximaciones al estudio de lo maravilloso en Huon de Bordeaux. Exlibris, (4), 151-157. http://revistas.filo.uba.ar/index.php/exlibris/ article/view/352/215

(2018). Cruces genéricos y de materias narrativas. Motivos tradicionales en Le roman d'Auberon y Huon de Bordeaux. Saga. Revista de Letras, (8), 1-19. http://sagarevistadeletras.com.ar/archivos/1.-Lacalle-1.pdf (2019). Vigencia de la novela histórica. Un recorrido por aspectos teóricos clave y una primera aproximación a la novela histórica de temática medieval. Estudios de Teoría Literaria. Revista digital: artes, letras y humanidades, (16), 180-19o. https://fh.mdp.edu.ar/revistas/index.php/etl/article/view/2650/3389

Lalanda, J.M. (Ed.) (2002). Huon de Burdeos. Madrid: Siruela.

Mujica Lainez, M. (2009) [1965]. El unicornio. Buenos Aires: Sudamericana.

Peralta, J.L. (2015). Huellas de disidencia homoerótica en El unicornio de Manuel Mujica Lainez. Revista chilena de literatura, (90), 197-222. http://dx.doi.org/10.4067/So718-22952015000200009 
Subrenat, J. (Ed.). (1973). Le roman d'Auberon. Ginebra: Droz.

Utz, R. (2017). Medievalism: A Manifesto. Leeds: Past Imperfect.

Vázquez, M.E. (1983). El mundo de Manuel Mujica Lainez. Conversaciones con María Esther Vázquez. Buenos Aires: Editorial de Belgrano.

Villordo, O.H. (1991). Manucho. Una vida de Mujica Lainez. Buenos Aires: Planeta.

Wilhite, V.M. (2011). La metamorfosis de un hada: Melusina en las versiones medievales de Jean d'Arras y Coudrette y en El unicornio de Mujica Lainez. Revista Forma, (3), 23-32. https://www.upf.edu/ documents/3928637/4018092/forma_volo3_04wilhite.pdf/occa56d6-d744-43c4-ao74-53d4c39b73fc 